\title{
DEUSES NA ENCRUZILHADA: hibridismo religioso em Um defeito de cor, de Ana Maria Gonçalves e The bondwoman's narrative, de Hannah Crafts
}

\section{Gods at the crossroads: religious hybridity in Um defeito de cor, de Ana Maria Gonçalves and The bondwoman's narrative, de Hannah Crafts}

Jeane Virgínia Costa do Nascimento ${ }^{1}$

Elio Ferreira de Souza ${ }^{2}$

\begin{abstract}
RESUMO: Um defeito de cor (2006) e The bondwoman's narrative (2002) são o corpus desse estudo. Ambas foram ambientadas no contexto da escravidão, o primeiro no Brasil e, o último, nos Estados Unidos. Apresentam como protagonistas Kehinde/Luísa e Hannah experienciando entre-lugares, mencionando a ancestralidade nas vivências de suas tradições. $O$ hibridismo manifesta-se pelos contatos entre senhores e escravizados, em que uma das consequências foi a ressignificação da religiosidade das identidades escravizadas. Para isso, definiu-se como objetivo desenvolver reflexões sobre o modo como as protagonistas ressignificaram suas identidades religiosas, diante dos vários contatos culturais ocorridos durante o período da escravidão. Kabengele Munanga (2015), Reginaldo Prandi (2001, 2015), W. E. B. Du Bois (1999) e Stefania Capone (2011) foram os referenciais teóricos desse estudo que foi feito por meio de levantamento bibliográfico. Espera-se que este estudo contribua para a compreensão das ressignificações das identidades religiosas do sujeito escravizado.
\end{abstract}

Palavras-chave: Cosmogonia. Entre-lugar. Hibridismo.

ABSTRACT: Um defeito de cor (2006) and The bondwoman's narrative (2002) are the corpus of these study. Both of them were set on the slavery context, the former in Brazil and, the later, in the United States. They presentes as protagonists Kehinde/Luísa and Hannah living in-betweens, mentioning the ancestrality in their traditions experiences. The hybridity is expressed by the meetings between masters and slaves, in which one of the consequences was the resignification of religiousness in enslaved identities. For that, it was defined as purpose to develop reflection about the way as the main identities resignified their religious identities, through of many cultural contacts occurred during the slavery period. Kabengele Munanga (2015), Reginaldo Prandi (2001, 2015), W. E. B. Du Bois (1999) and Stefania Capone (2011) were the theoretical references of these study which was done by bibliographic

\footnotetext{
${ }^{1}$ Mestre em Letras pela Universidade Estadual do Piauí - UESPI (2018). Área de concentração Literatura, Memória e Relações de Gênero. E-mail: jeanevirginia@uol.com.br

${ }^{2}$ Doutor em Letras pela Universidade Estadual de Pernambuco (UFPE). Professor do Mestrado e da Graduação em Letras da Universidade Estadual do Piauí (UESPI). E-mail: professorelioferreira@yahoo.com
}

Cadernos Cajuína, V. 3, N. 2, 2018, p. 95 - 106. 
survey. It is expected that this study contributes for the comprehension of religious identities ressignifications of enslaved person.

Key-words: Cosmogony. In-between. Hibridity.

\section{INTRODUÇÃO}

A diáspora africana provocou mudanças de ambiente que propiciaram o contato entre diferentes culturas. Porém, em sua terra natal, o africano não vivia em um meio de desorganização consoante ao que colonizador pregava. W. E. B. Du Bois esclarece que "a história social do Negro não começou na América. O Negro foi trazido de um meio social definido" (DU BOIS, 1999, p. 245). Quanto às tradições, o referido autor reitera que, para o africano, "sua religião era o culto à natureza, com uma profunda crença nas influências invisíveis circundantes, boas e más, e seu culto exercia-se por meio da magia e do sacrifício" (Idem, p. 246). Essa crença na ligação com a natureza e a ancestralidade diferenciou os cultos africanos daqueles de origem cristã.

O pensamento de $\mathrm{Du}$ Bois esclarece que a religiosidade era um fator determinante na vida africana, inclusive no que diz respeito aos aspectos não religiosos do cotidiano. A sociedade africana era de base familiar e as decisões a serem tomadas deveriam ter a participação de todos, inclusive daqueles que já não pertenciam ao Aiê (mundo material). As "influências invisíveis" eram a efetivação da ancestralidade. Com a diáspora, vários espaços intersticiais foram possibilitados e, com isso, várias culturas se encontraram e puderam ser classificadas como colonizadora e colonizada. Esta última foi bastante silenciada pela primeira, mas seus sujeitos foram os que mais buscaram estratégias para se adaptar às situações de opressão impostas pela tradição hegemônica.

Tal contato entre culturas favoreceu a ocorrência dos entre-lugares. Homi Bhabha em O local da cultura expõe que "esses 'entre-lugares' fornecem o terreno para a elaboração de estratégias de subjetivação, que dão início a novos signos de identidade e postos inovadores de colaboração e contestação, no ato de definir a própria ideia de sociedade" (BHABHA, 2001, p. 20). Essas estratégias, que podem 
ser individuais ou coletivas que, como resultado, geraram relações harmônicas, conflituosas ou ressignificadas.

Os trânsitos diaspóricos proporcionaram o encontro entre diversas identidades manifestadas por meio da religiosidade no entre-lugar do navio negreiro é uma das representações do caráter multifacetado do romance Um defeito de cor. À medida que esses deslocamentos acontecem, a religiosidade da protagonista Kehinde-Luísa se ressignifica. Esses deslocamentos permitiram em The bondwoman's narrative, a ocorrência de um entre-lugar, a mansão Lindendale, onde a protagonista manifesta sua ligação com a natureza ao relacionar fenômenos naturais e sobrenaturais com acontecimentos futuros, mas que, ao longo da trama, ressignifica sua relação com o mundo por meio da imposição da religião cristã pelo colonizador branco. Em ambos, reitera-se a importância da ancestralidade e da ligação com a natureza para a constituição das identidades principais das obras.

Diante do contexto apresentado problematizou-se a seguinte questão: como as identidades cosmogônicas e religiosas das protagonistas das obras Um defeito de cor e The bondwoman's narrative? A partir dessa pergunta definiu-se como objetivo desenvolver reflexões sobre o modo como as protagonistas ressignificaram suas identidades cosmogônicas e religiosas, diante dos vários contatos culturais ocorridos durante o período da escravidão.

Foram utilizadas para embasar este capítulo, as teorias de autores consagrados que versaram sobre os estudos culturais, voltados para as tradições africanas e cristãs e o hibridismo. Para contextualizar, ao longo das exposições teóricas serão feitos diálogos com as obras que compõe o corpus deste estudo.

\section{DEUSES NAS ENCRUZILHADAS: RELIGIOSIDADES HÍBRIDAS EM UM DEFEITO DE COR E THE BONDWOMAN'S NARRATIVE}

2.1 Entre santos e orixás, eu preservo minha memória: do Catolicismo ao Candomblé em Um defeito de cor

"O corpo, esse que a gente toca e vê, é chamado de ara, e quando morremos ele volta a se fundir com a natureza" (GONÇALVES, 2011, p. 577). 
A ligação entre homem e natureza é marcante nas representações religiosas de origem africana. Destaca-se ainda a forte ligação com os antepassados e com a energia vital superior proveniente dos orixás. O orixá geral gera o princípio e o orixá de cabeça define o destino e personalidade do indivíduo. Para os africanos, somos parte sempre da mesma família terrena menor (do Aiê), mas que também pertencemos a uma família maior a do Orum (mundo espiritual) ligada ao grande orixá e as forças da natureza que regem o destino. Com a imposição dos valores morais eurocêntricos, os ritos e crenças africanos tiveram sua essência desfigurada pelo pensamento do colonizador.

Historicamente, os povos escravizados eram obrigados a adotar a religião dos seus senhores. Obrigação essa, determinada pela recusa do povo europeu em reconhecer o estilo de vida africano e suas particularidades. Kabengele Munanga apresenta que os europeus viam os negros como profundamente corruptos e pecaminosos (MUNANGA, 2015, p. 29). Além disso, para os europeus dos séculos XVI e XVII, "o homem não deve temer a escravidão do homem pelo homem, e sim sua submissão às forças do mal" (Idem), ou seja, compreende-se que a partir do pensamento europeu, o estilo de vida africano era inferior e selvagem, que a escravidão era uma forma de "pagar pelos pecados" e que a adoção do catolicismo poderia salvar esses povos.

Em Um defeito de cor, durante a viagem da África ao Brasil, Kehinde, ainda criança, foi aconselhada pela avó para que ela não esquecesse de suas tradições orixás. Ao chegar no Brasil, ela recusa-se a aceitar o batismo católico e arrisca a vida para manter suas tradições. Tal situação demonstra a resistência em aceitar a religião hegemônica:

Nós não víamos a hora de desembarcar [...] mas, disseram que antes teríamos que esperar um padre que viria nos batizar, para que não pisássemos em terras do Brasil com a alma pagã. Eu não sabia o que era alma pagã, mas já tinha sido batizada em África, já tinha recebido um nome e não queria trocá-lo, como tinham feito com os homens. Em terras do Brasil, eles tanto deveriam usar os nomes novos, de brancos, como louvar os deuses dos brancos, o que eu me negava a aceitar, pois tinha ouvido os conselhos da minha avó. Ela tinha dito que seria através do meu nome que meus voduns iam me proteger [...] amarrei meu pano em volta do pescoço, e saí correndo pelo meio dos guardas. Antes que algum deles pudesse me deter, pulei no mar. A água estava quente e eu não sabia nadar direito. Então lembrei de lemanjá e pedi que ela me protegesse, que me levasse até a terra [...] Ir para ilha e fugir do padre era exatamente o 
que eu queria, desembarcar usando o meu nome, o nome que minha avó e a minha mãe tinham me dado e com o qual me apresentaram os orixás e os voduns (GONÇALVES, 2011, p. 62-63).

A crença na verdade ancestral e nos orixás permitiu à protagonista pensar que ela não era inferior e nem precisava de outra religião para se sentir importante. Além disso, ao colocar em prática os conselhos dados pela avó, Kehinde valorizou o respeito à palavra dos mais velhos e preservou as relações familiares, mesmo após a morte destes.

Os africanos procuraram preservar a tradição dos orixás por meio do Candomblé que foi evidenciado no romance de Gonçalves. Uma das formas de resistência retratada no romance Um defeito de cor foi o sincretismo religioso. A religião católica foi imposta pelo colonizador ao povo escravizado. Este último, por sua vez, não quis abdicar completamente de suas práticas religiosas e encontraram por meio da associação entre orixás e os santos católicos uma forma de celebrar suas divindades, ou seja, de resistir e preservar esse marcante traço cultural que é a religiosidade de um povo.

A associação ocorre a partir das nominações dos componentes de uma casa de cultos fazem uso de termos como pai-de-santo, mãe-de-santo e filho-de-santo, mas o "santo" na verdade é o orixá que rege a cabeça de cada praticante desta religião. Prandi nos apresenta outra percepção dessa associação santo-orixá:

\footnotetext{
O sincretismo representa a captura da religião dos orixás dentro de um modelo que pressupõe, antes de mais nada, a existência de dois polos antagônicos que presidem todas as ações humanas: o bem e o mal; de um lado a virtude, do outro o pecado. Essa concepção, que é judaico-cristã, não existia na África (PRANDI, 2001, p. 51).
}

Esse maniqueísmo pregado pelas religiões cristãs reiterou a demonização das religiões de matriz africana. Para o europeu opressor, fazia-se necessário afirmar que a religião deles era certa, que traria a glória e a salvação eterna. Já a do africano era a errada, o que explicava o "atraso" dos africanos e a necessidade da escravização para sua evolução. O demônio é uma figura pertencente aos dogmas das religiões de base cristã e este, por ser a mais forte representação das forças do mal, foi associado ao Candomblé e, mais tarde à Umbanda.

Ferretti (2013, p. 45) comenta que "é a equivalência das divindades que dá a ilusão da conversão católica, pois, 'sem renunciar aos seus deuses ou orixás, o 
negro baiano tem profunda devoção". Assim, cada orixá possui um santo católico equivalente que varia de acordo com a região do Brasil. Para os negros durante o período da escravidão, relacionar estas duas práticas religiosas foi um modo de preservar e vivenciar essa importante herança ancestral africana.

Até a Esméria tinha lá os seus orixás, mesmo já sendo acostumada aos santos dos brancos e tendo simpatia por alguns deles, como São Benedito, que era preto como nós, ou Nossa Senhora da Conceição, que se reza como lemanjá, assim como São Jorge é Xangô e Santo Antônio é Ogum, ou São Cosme e Damião, que são os Ibêjis (GONÇALVES, 2011, p. 90).

Reginaldo Prandi comenta que "na diáspora africana, os mitos iorubás reproduziram-se na América, especialmente cultuados pelas religiões dos orixás no Brasil” (PRANDI, 2001, p. 24-25). Tais práticas e rituais são descritos e relatados no romance em estudo. Com isso, mesmo com a imposição da religião cristã pelo colonizador, percebe-se a resistência da pessoa negra escravizada. Entretanto, com o deslocamento de Luísa do Brasil para Uidá, África, a identidade cosmogônica da protagonista se ressignificou ao ponto de ela priorizar o batismo cristão, mas sem esquecer a cerimônia do nome; contudo, essa última ficou em segundo plano:m manter seus ritos e tradições.

\begin{abstract}
Antes de o John partir para Freetown, sem data para voltar, resolvemos aproveitar a presença do padre no forte e batizar as crianças. No dia em que fui conversar com ele, um velho português chamado padre José Maria, levei minha Bíblia para benzer. Achei que assim seria mais bem recebida, e de fato fui, pois ele se surpreendeu por haver alguém ali que conhecia um pouco melhor a Igreja Católica [...] durante a ausência de John, levei os lbêjis até a casa da l̀ya Kumani, que fez uma cerimônia do nome para eles, como eu tinha feito para você e para o Banjokô. Encomendei também o sacrifício de dois carneiros para Xangô, um para cada, e mandei fazer um ebó para Nanã, a mãe de todos, agradecendo por ter corrido tudo bem no período em que eles estiveram dentro da minha barriga e no nascimento, e pedi que continuasse olhando por eles (GONÇALVES, 2011, p. 791-792).
\end{abstract}

Nesse retorno, a protagonista preferenciou o catolicismo como forma de autoafirmação e até demonstração de sucesso de quem vivenciou a escravidão e conseguiu retornar às suas origens. Eduardo de Assis Duarte complementa "tantas identificações em processo apontam para o trânsito diaspórico a abalar o império da essência e do uno identitários" (DUARTE, 2009, p. 30), ou seja, a protagonista 
ressignificou sua essência ancestral e seguiu a crença do que ela já havia vivenciado em vários lugares no Brasil. Ela optou pela identidade que lhe fosse mais conveniente que, no caso do fragmento, foi apropriar-se da religião católica como sua crença principal.

Percebe-se que com os deslocamentos, a protagonista passou por diversas trocas de experiências que provocaram diversas ressignificações de suas práticas religiosas. Essa religiosidade transitou na resistência à assimilação da religião do colonizador, na chegada ao Brasil. A associação entre santos e orixás representou a falsa assimilação da religiosidade imposta pelo colonizador. O retorno à África foi marcado pela assimilação e pela escolha preferencial pela prática da religião católica. Assim, foi possível observar que a identidade religiosa da protagonista foi marcada pelas práticas hibridizadas das principais religiões das quais ela teve contato.

2.2 Identidades hibridizadas: a religião colonial e o inconsciente ancestral em The bondwoman's narrative

Eu encontrei motivos para consolação e encorajamento, que nós devemos exercer nossa fé e paciência e confiar em Deus. Como isso alivia minha miséria e até mesmo derrota minhas dores $^{3}$ (CRAFTS, 2014, p. 60, tradução nossa).

A religiosidade no romance The bondwoman's narrative foi apresentada sob duas formas: manifestação do inconsciente ancestral e hibridização da religião do colonizador pelo colonizado. Esta última forma é referenciada na epígrafe acima. As práticas ancestrais foram constantemente desdenhadas pelo pensamento hegemônico. Uma das formas de expressão religiosa mais evidente para os escravizados e libertos foi o protestantismo. Possivelmente, devido à própria forma de colonização dos Estados Unidos, predominantemente protestante.

A religião também era um modo de consolação para a pessoa escravizada e uma forma de enfrentar o sofrimento vivido por esta. Entretanto, "a maioria dos proprietários de terra recusava uma instrução religiosa para seus escravos, com medo de que o batismo os emancipasse" (CAPONE, 2011, p. 32). A protagonista foi

\footnotetext{
${ }^{3}$ I found motives for consolation and encouragement, that we must exercise faith and patience and an abiding trust in God. Oh, the blessedness of such heavenly trust - how it comforts and sustains the soul in moments of doubt and despondency - how it alleviates misery and even subdues pain (CRAFTS, 2014, p. 60).
}

Cadernos Cajuína, V. 3, N. 2, 2018, p. 95 - 106.

ISSN: 2448-0916 
alfabetizada, de forma escondida de seus senhores. Ao ser descoberta vive o desespero não somente com sua própria punição, mas com a punição daqueles que a instruíram. O principal livro de aprendizado era a Bíblia. Além disso, foi orientada para ser boa e corajosa. Esse incentivo era uma forma de ela se resignar diante da condição de escrava:

A vida de escravo não é prazerosa, mas eu tinha prometido a mim mesmo para sempre olhar pelo lado bom das coisas, ser aplicada, disposta, boa de coração, fazer algo bom de modo humilde, e conquistar amor se eu puder. "Eu sou uma escrava", portanto meus pensamentos divagariam. "Eu nunca saberia ser brilhante, nem rica; eu não posso alcançar uma posição elevada na sociedade, mas eu posso fazer minha obrigação, e ser boa na certeza e esperança da recompensa eterna ${ }^{4}$ (CRAFTS, 2014, p. 11, tradução nossa).

Diante desta situação, na visão do colonizador, entende-se que mesmo em escravidão, a protagonista também seria salva por Deus se ela tivesse fé nele. Essa é a chamada dupla consciência esclarecida por Du Bois (1999, p. 39) como "esse sentido de sempre olhar a si próprio através dos olhos de outros, de medir um sentimento através da métrica de um mundo que o contempla com divertido desprezo e pena". O escravizado passou a naturalizar esse pensamento que fez com que o mesmo se sentisse confortado diante do sofrimento. A percepção de si mesmo por meio do que outras pessoas definem como correto e justo.

Outro aspecto a ser ressaltado foi o que identifica o hibridismo do africano colonizado. As histórias relacionadas com essa ancestralidade eram comumente relatadas por pessoas na condição de cativas na narrativa e, portanto, omitidas aos senhores, já como demonstração de silenciamento. Sobre a ligação com a tradição ancestral e a natureza, W. E. B. Du Bois enfatiza que:

O Negro já foi citado muitas vezes como um animal religioso - um ser com uma profunda natureza emocional que se volta instintivamente para o sobrenatural. Dotado de imaginação rica e ardente e de uma aguda e delicada apreciação da Natureza, o africano transplantado viveu em um mundo habitado por deuses e demônios, duendes e feiticeiros; cheios de estranhas influências - do Bem a implorar, do

\footnotetext{
${ }^{4}$ The life of a slave at best is not a pleasant one, but I had formed a resolution to always look on the bright side of things, to be industrious, cheerful, and true-hearted, to do some good though in an humble way, and to win some love if I could. "I am a slave" thus my thoughts would run. "I can never be great, nor rich; I cannot hold an elevated position in society, but I can do my duty, and be kind in the sure and certain hope of an eternal reward.["] (CRAFTS, 2014, p. 11).
}

Cadernos Cajuína, V. 3, N. 2, 2018, p. 95 - 106.

ISSN: 2448-0916 
Mal a propiciar. A escravidão, nesse sentido, representava para ele e sobre ele o sombrio triunfo do Mal (W. E. B. Du Bois, 1999, p. 248).

Elementos como a chuva, o estado do céu e rangidos de árvores foram constantemente associados a ocorrência de bons ou maus acontecimentos na obra. Desse modo, observa-se que, mesmo que de modo intuitivo, a protagonista preservou a relação entre ser humano e natureza, que é comum a cultura africana:

Todos os escravizados conheciam a história daquela árvore. Não havia sido escondido deles uma influência tempestuosa e sobrenatural que se supunha pertencer a ela. Plantada pelo senhor Clifford, ela cresceu e floresceu muitíssimo sob os cuidados dele. Mas o homem velho e rigoroso foi duro para seus escravos e poucos em nossos dias poderiam ser tão cruéis, enquanto o linden (a árvore) foi escolhida como cenário onde as torturas e punições eram aplicadas. Muitas vezes, suas raízes foram adubadas com sangue humano. Escravos tinham sido amarrados a seus troncos para serem chicoteados e às vezes enforcados em seus galhos ${ }^{5}$ (CRAFTS, 2014, p. 20-21, tradução nossa).

Neste fragmento, verifica-se que a intuição ancestral é presente na consciência do escravizado, mesmo em um ambiente que havia a imposição do pensamento hegemônico. Para Erisvaldo Pereira dos Santos, a relação entre homem e natureza pode ser compreendida por meio da identificação do orixá da pessoa (SANTOS, 2015, p. 47). Embora não haja menção a orixás em The bondwoman's narrative, a percepção de elementos naturais foi uma forma, mesmo que inconsciente, de expressão da ancestralidade tão presente na cultura africana, portanto o referido autor afirma:

Há um domínio ou força da natureza que se refere a cada divindade, Por isso, mar, rios, pântanos, cachoeiras, matas, árvores, pedreiras, ventos, chuvas, trovões, raios e metais fazem parte das referências míticas e sagradas das religiões de matrizes africanas. Essas referências fazem com que haja uma maior relação de interdependência entre homem e natureza (SANTOS, 2015, p. 47).

\footnotetext{
${ }^{5}$ The servants all knew the history of that tree. It had not been concealed from them that a wild and weird influence was supposed to belong it. Planted by Sir Clifford, it had grown and flourished exccedingly under his management. But the stern old man was a hard master to his slaves and few in our days could be so cruel, while the linden was chosen as the scene where the tortures and punishments were inflicted. Many a time hat its roots been manured with human blood. Slaves had been tied to its trunk to be whipped or sometimes gibbeted on its branches" (CRAFTS, 2014, p. 2021).
}

Cadernos Cajuína, V. 3, N. 2, 2018, p. 95 - 106. 
As religiões negras se pautaram na coletividade conforme era comum nas tribos africanas. Segundo Stefania Capone (2011, p. 30), "esse aspecto comunitário que ligaria a religião negra norte-americana a seu passado africano, em clara oposição com o Ocidente, dominado pelo individualismo e pela perda de qualquer ponto de referência coletivo". Em The bondwoman's narrative, foi visível a assimilação da religião cristã pela protagonista que sempre que possível entrega seu próprio destino a Deus e, na maioria das vezes, foi atendida. Contudo, essa religiosidade hegemônica foi combinada com características da cultura negra ancestral devido a ocorrência de inspirações ligadas a fenômenos da natureza.

Em outra situação na obra, a protagonista tornou-se praticante da Igreja Metodista, após a fuga para liberdade. Essa religião foi buscada por muitos libertos devido suas características abolicionistas. A igreja determinava que seus membros não possuíssem escravos e, portanto, deveriam libertá-los. Houve resistência entre alguns praticantes, especialmente pelos praticantes da igreja na região sul estadunidense. A igreja permaneceu dividida até o ano de 1944. Hannah assim descreve sua vida na igreja:

Eu preciso descrever a igreja pequena onde todos nós nos encontrávamos, e a felicidade que nós experimentávamos ao ouvir as palavras da verdade divina; e como eu não poderia, nem se eu quisesse, suficientemente apresentar a bondade de todos para comigo, a ternura e o amor com que minhas crianças da escola me consideravam ${ }^{6}$ (CRAFTS, 2014, p. 246, tradução nossa).

Ao longo da história, as religiões africanas tiveram dois destinos no contexto diaspórico África-América: na América Central e do Sul buscou-se preservar ou ressignificar os mitos, os ritos, os deuses cultuados no continente original; na América do Norte houve o apagamento e, ainda, a adoção da religião do colonizador europeu e com a criação da Igreja Negra e suas variações, conforme Stefania Capone (2011, p. 53) reitera "a expressão religiosa dos negros norte-americanos se caracteriza por sua multiplicidade, e não por sua uniformidade".

Em The bondwoman's narrative foi observado que Hannah não possuía uma referência religiosa ancestral. A protagonista foi apresentada para a religião cristã

\footnotetext{
${ }^{6}$ Need I describe the little church where we all go to meeting, and the happiness we experience in listening to the words of Gospel truth; and as I could not, if I tried, sufficiently set forth the goodness of those about me, the tenderness and love with which my children of the school regard me (CRAFTS, 2014, p. 246).
}

Cadernos Cajuína, V. 3, N. 2, 2018, p. 95 - 106.

ISSN: 2448-0916 
por agregados da fazenda e manteve a Bíblia como seu livro de aprendizado. O contato com outras identidades escravizadas na fazenda Lindendale fez com que ela despertasse para a intuição ancestral ao associar fenômenos naturais com eventos bons ou ruins. Quando liberta converte-se a Igreja Metodista. Assim, verifica-se que os trânsitos vivenciados por Crafts propiciaram a hibridização de suas práticas religiosas.

\section{CONCLUSÃO}

Diante das diversas representações religiosas apresentadas, o estudo das obras Um defeito de cor e The bondwoman's narrative evidencia os vários desdobramentos que a religiosidade do povo africano em diáspora foi vivenciada. Assim, o corpus desse estudo contextualizou várias formas de ressignificação e a hibridização de suas práticas religiosas.

Os espaços em que as protagonistas trocaram experiências com outras identidades, sejam eles praticantes da tradição africana ou praticantes da tradição cristã, foram decisivos para que o colonizado repensasse seus modos de perceber as suas próprias práticas religiosas.

Em Um defeito de cor, o hibridismo religioso foi representado pela prática do sincretismo religioso e escolha preferencial pelo Catolicismo como religião a ser praticada na África. Em The bondwoman's narrative, o hibridismo foi visto na assimilação da religião cristã, manifestada pela religião evangélica, juntamente com a vivência de sua intuição ancestral na percepção da natureza e da ancestralidade.

Conclui-se que o africano transplantado para as Américas tornou-se um sujeito religioso híbrido devido aos vários deslocamentos e, por conseguinte, vários contatos com identidades escravizadas ou escravizantes. Este contato permitiu trocas de experiências que propiciaram este hibridismo não somente sob a prática religiosa, mas também em relação a outros aspectos da vida do colonizado. 


\section{REFERÊNCIAS}

BHABHA, Homi K. O local da cultura. Belo Horizonte: Editora UFMG, 2001.

CAPONE, Stefania. Os Yoruba do Novo Mundo: Religião, Etnicidade e Nacionalismo Negro nos Estados Unidos. Tradução de Márcia Atálla Pietroluongo. Rio de Janeiro: Pallas, 2011.

CRAFTS, Hannah. The bondwoman's narrative. Organização Henry Louis Gates Jr.; Gregg Hecimovich (Org.). New York: Grand Central Publishing, 2002. (2014).

DUARTE, Eduardo de Assis. Na cartografia do romance afro-brasileiro: "Um Defeito de Cor" de Ana Maria Gonçalves. In: Culturas e diásporas africanas. Organização: Cláudia Regina Lahni et al. Juiz de Fora: UFJF, 2009.

DU BOIS, W. E. B. As almas da gente negra. Tradução, introdução e notas de Heloisa Toller Gomes. Rio de Janeiro: Lacerda Ed., 1999.

FERRETTI, Sérgio Figueiredo. Repensando o Sincretismo: Estudo sobre a Casa das Minas. São Paulo: Editora da USP; São Luís: FAPEMA, 2013.

GONÇALVES, Ana Maria. Um defeito de cor. 7ed. Rio de Janeiro: Record, 2006. (2011).

MUNANGA, Kabengele. Negritude: Usos e sentidos. 3. ed. Belo Horizonte: Autêntica Editora, 2015.

PRANDI, Reginaldo. Mitologia dos orixás. São Paulo: Companhia das Letras, 2001.

PRANDI, Reginaldo. Sincretismo católico e a demonização do orixá Exu. Revista USP, São Paulo, n.50, p. 46-63, junho/agosto, 2001.

SANTOS, Erisvaldo Pereira dos. Formação de professores e religiões de matrizes africanas: um diálogo necessário. 2ed. Belo Horizonte: Nandyala, 2015. 